\title{
Start-Up Entrepreneurs and University Students in a Co-Learning Mode
}

Learning effects of a collaborative entrepreneurial coaching program

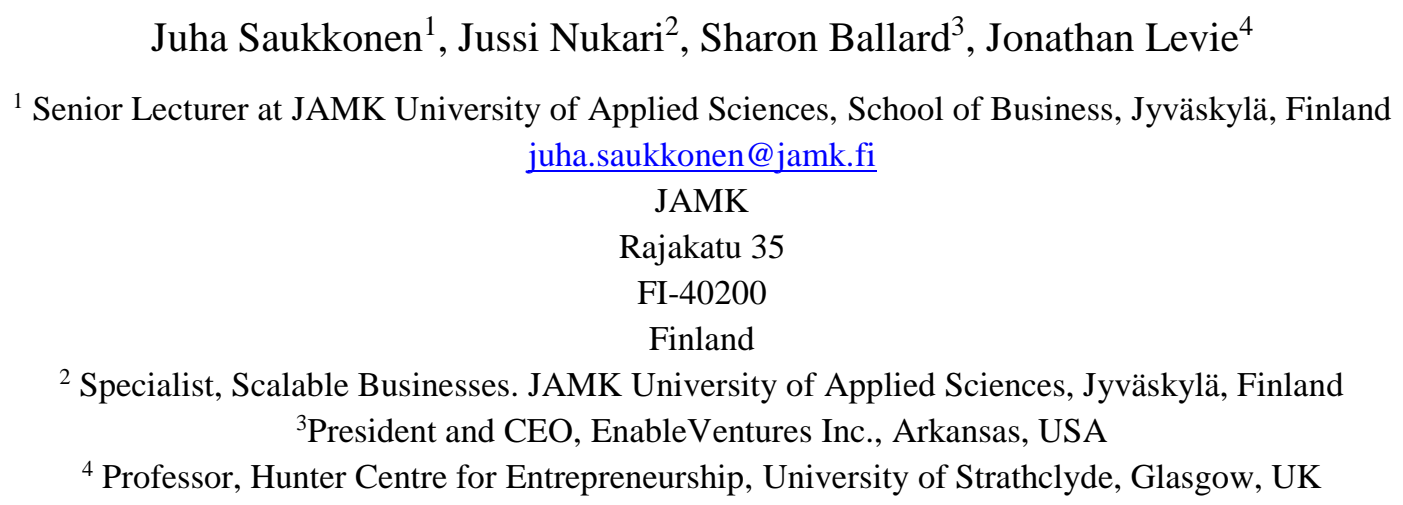

\begin{abstract}
Start-up companies have been recognized as key drivers of wealth and job creation. Thus, a significant number of students now in universities will find their future employment in start-up companies, or will found them. Success in that environment requires specific set of skills. There is a growing supply of university education for new venture creation as well as demand for interaction between universities and start-up ventures to transfer knowledge between them. This paper aims to evaluate othe potential of a holistic collaborative entrepreneurial learning between start-up companies and students.

In the empirical part, the impacts of the learning arrangement to the self- assessed capabilities and the participants' assessment of critical capabilities for start-up success (pre-, post-, and 1 year post-program) were measured. The results show that an impact on assessed capabilities can be achieved and the two distinct groups can learn together, but questions remain in terms of learning retention.
\end{abstract}

Keywords Start-Up, collaboration, coaching, capabilities, learning 


\section{Introduction}

"A Start-Up is a human institution designed to create a new product or service under conditions of extreme uncertainty" (Ries, 2011:27).

Since the economic doldrums of circa 2008, the most important engine of net job creation in most economies has been SMEs, as confirmed in the special report "Are EU SMEs recovering from the crisis? Annual Report on EU Small and Medium Sized Enterprises 2010/2011“ by European Commission (EC) (2012). To give a concrete example EC survey stated that SMEs provide a vital contribution to the European economy, by being responsible for more than two thirds of the total employment (in the private sectors) and creating $85 \%$ of the net job growth. This impact of SMEs to job creation has prevailed longer than the current doldrums in economy: between 2002 and 2010, the SMEs had a much higher employment growth rate (1\% annually) than the large enterprises $(0.5 \%)$. Also, the annual employment growth rate of SMEs was on average higher than the growth rate of the total EU population - about $0.4 \%$ annually over 2002/2010- and growth rate of the total active population in EU - 0.8\% for the same period (EC 2012). Kaufmann Foundation in US $(2010,2014)$ has addressed the importance of specific type of SMEs - startups in net job creation.

Thus, by providing relevant support knowledge to these evolving companies universities can have a major impact on development of start-ups, employment prospects of their students and to the whole society. To make this potential impact a reality, new formats of co-learning between universities and start-up companies need to be developed. And since the dynamics of start-up companies are different to established industries (e.g. Mohr et al., 2010), these novel approaches mean that universities also need to step out from their comfort zone to design and try new modes of working - they become partly start-ups themselves, if definition by Ries is followed. Collaboration or industries and academia is not a risk-free operation, as Jones and Clulow (2012) pointed out: "Though industry-academic collaborations can be challenging, the benefits certainly outweigh the risks." Jones and Clulow did not specify which of the many types of collaboration they had in mind - and the industry-academic collaboration covers a range of modes from joint research to tech transfer to joint venturing in business. The comment of Jones and Clulow should thus be seen from a general viewpoint, not particularly from start-up angle. To understand the specific risks and benefits of novel modes of collaboration such as the co-learning with start-up companies - scope of this paper - and to make continuous improvements to those processes their learning results, business impacts and learning retention need to be analyzed and assessed.

The aim of this paper is to introduce an intensive 8-week coaching program developed for first-time science - and technology-based entrepreneurs and implemented in many universities in US and in Europe, and analyse the effects of the program on a cohort of students and entrepreneurs in JAMK University of Applied Sciences, Finland. The 
unique feature of the program is that on the one hand it helps start-up entrepreneurs to develop an overall strategic plan, articulate and defend a business model for the nascent phase of their company-to-be, aiming for growth and a move into international markets, and on the other hand it simultaneously forms part of a full-semester specialization course of High Tech Management for a multi-national group of bachelor's students, who act as "assistant coaches" of the entrepreneurs, guided by faculty members who are certified instructors in the method.

In the next section, we demonstrate a theoretical rationale for an experiential, "structured facilitation" approach to enterprise education. In our methodology section, we explain how we measured the self-efficacy of students and entrepreneurs before the program began, at the end of the program, and one year after the program. Our results show that it is possible to create co-learning modes where students and entrepreneurs can learn together and support each other's learning. The results also show that notable learning results can be achieved in an intensive coaching arrangement that differs from standard university teaching practices. We conclude by discussing the prerequisites for success of similar type of co-learning initiatives and ways to further improve both the practices of entrepreneuship education as well as propose angles to research on entrepreneurship education for the future.

\section{Theoretical base}

\section{Specific nature of technology-based start-up companies}

Not all entrepreneurs are the same. The issues they will face may vary by stage of development of the business and by industry sector. The case studied in this paper is an intensive coaching program aimed at first-time science and technology -based entrepreneurs. Mohr et al. (2010) characterized High Technology ventures as facing high market uncertainty, high technological uncertainty and high competitive volatility. Fine (2008) suggested that the pace of change in the value chain structures of industries and timeframe in which the value chain must operate in has been increasing throughout time as new industries evolve. These characteristics set a number of challenges to teaching and learning for High Technology Business. For example, learning from past examples such as historical case studies has limited applicability to present conditions. Indeed, since the future workplaces of many students will be in companies and industries that are recently born or even to be born in the near future, then "live projects - solving research and development projects assigned by enterprises - have also a meta-purpose from the educator's point-of-view: In addition to offering networking opportunities and working-life based learnings to students, it offers the teacher or learning facilitator an opportunity to 
mirror the relevancy of the other theories and tools taught in other modes of learning". (Saukkonen, 2014:7)

High Technology-based companies vary in size - of their sales, operations and organizations. Mature firms have their specific departments of research and development, business intelligence etc., potentially leading to a smaller need to gain new information and knowledge via education-enterprise interaction. Non-mature start-up companies however are typically short of human resources. Furthermore, the dynamic capabilities needed for success vary as ventures develop (Marmer et al., 2011). This indicates that technologybased start-up companies can take significant benefits from enterprise-education interaction since their own of vital knowledge are limited in size and variety, especially for firsttime entrepreneurs. Also their projects tend to include many turns (pivots) and questions are more open-ended, leaving room for students' own initiatives and methods of getting results. This phenomenon of flexibility and mobility of the goals is captured by Ries (2011) in his definition of a start-up as "an organization dedicated to creating something new in term of extreme uncertainty". These redirections of the project aim and goals provide learners a realistic view of life in the business environment the companies of this kind are operating.

High Technology business is a global marketplace where solutions have potential to spread rapidly, even virally. Thus international student groups with skills in multiple languages, knowledge of cultures and with skills of modern data search methods, can assist substantially a non-mature technology firm with the output of their learning. .

\section{Education for Entrepreneurship}

Entrepreneurship as a topic of education is at the same time widely implemented and debated. Scholars and practitioners differ on what needs to be learned in entrepreneurship-related courses and how the learning can be achieved and supported/facilitated. One commonly promoted aim of entrepreneurship education is "fostering entrepreneurial mindset" (EM). As Kleine and Yoder (2011) state, there is ambiguity in the literature on what exactly makes an EM, but nevertheless learning process designers must operationalize EM in an appropriate way to create educational activities that foster it. To give some practice-based clarity to EM (M stands for Mindset for some authors and Motivation for others), a recent review of the literature by Kauffman Foundation (2015) suggests that the most commonly explored constructs in EM research include:

- need for achievement

- risk taking

- tolerance to ambiguity

- locus of control 
- self-efficacy

- goal setting

These streams of research can naturally be interpreted to give also guidance what kind of impacts entrepreneurship education should impose on learning process participants. And they do not need to contrast with the way education has recently developed. According to Arum and Roska (2011), cultivating critical and creative thinking is regarded by many as the primary purpose of undergraduate college education, while Kleine and Yoder (2011) argue that the ability to think in a creative and critical way is fundamental to entrepreneurial activity. So a match can be made between processes of education of entrepreneurs and undergraduate students. The list demonstrates that many (if not all) of these issues cannot be learned from transmissive teaching methods but are rather achieved as by-products of working on entrepreneurial activity.

Success as an entrepreneur is not due to mindset alone. As Gompers et al. (2006) demonstrate, entreprenurship is a skill. Gompers et al. prove their point by stating that serial entrepreneurs who have succeeded in the past are more likely to repeat success than firsttime or failed entrepreneurs - so it is not experience but learned skills that can be reused (Ibid.). And skills can be taught, although an optimal learning process set-up is likely to differ from that of more traditional parts of business education.

One popular method of enriching the teaching approach in entrepreneurship is to expose the learners to stories and cases of discovery (of opportunities and solutions) and exploitation of entrepreneurial opportunities. This approach helps students by providing examples the students can relate to when encountering issues such as market opportunities and resource gaps in their professional future. According to Fiet (2000), such examples support students to create understanding of what is possible and what is feasible to be done in the situations they will encounter later. Aronsson (2004) and Garavan and O'Cinneide (1994) have pointed out that educational programs that are highly specialized in a single technical domain or a specific profession are not well suited to provide broad-based and practice-oriented training required to teach entrepreneurial skills. Thus training programs aiming at enhancing entrepreneurship potential should focus on high practice-orientation, addressing a broad set of managerial, leadership and organising skills. This quest for practice-based and practice-orientation has clear parallels with the concept of experiential learning used in pedagogical literature.

Corbett (2005) pointed out that experiential learning in which (following the thoughts of Luckmann, 1996) the learner constructs knowledge, skills and value from direct experiences "suits the entrepreneurship arena much better than the alternative behavioural learning approach of stimulus-response". However, the Kolb learning cycle (Kolb, 1984) suggests that entrepreneurs may learn best through a combination of active experiencing 
and generalizing their learning through appreciation of a theory. So having a live entrepreneurial business to work on and learn in has the upper hand over standard transmissive or even ready-made case-based teaching methods.

In summary, the scholarly work on the subject suggests that entrepreneurship can be taught, and at its best it can be done in a way that serves the needs of both entrepreneurs and undergraduate students (and the educational institutions to which the demand of more intensive participation in wealth creation is made). Achieving the optimal learning outcome requires that the learning process contain strong practice-orientation and elements of experiential learning.

\section{Collaborative learning in university-company interaction}

Teaching students about and for entrepreneurship is a common practice, but less entrepreneurial learning programs are implemented in a manner that bring external (to the university) entreprenurs into same learning process with students, making entrepreneur education part of the phenomenon of university-company interaction.

The so-called Triple Helix was coined by Etkowitz and Leyersdorff (1995) - as a systemic triangle where government, academic institutions and business are in a constant interplay, and forecast that academia would and should engage in deeper and wider collaboration with business. Universities and industry that have been traditionally distinct institutional spheres, are assuming tasks that udesa to be largely the territory of the other (Ibid.). As a sign of the movement towards Triple Helix, governments offer incentives, on the one hand, and pressing academic institutions, on the other, to extend their scope from traditional functions of cultural memory, education and research and make a more visible contribution to "wealth creation."

In addition to the growing pressure on universities to collaborate with business, traditional or "transmissive" learning methods (Brown et al. 2014) have been partly replaced or complemented by a multitude of new pedagogical methods (e.g. Gibbs, 2010; Astin, 1993). Many of these new methods focus on improved learning outcomes via two characteristics less common among traditional teacher-led knowledge dissemination methods:

1) Improved student engagement

2) Bringing real-life connections to the learning environment.

Student engagement in summary can be understood as the intensity with which learners engage in the learning process of which they are a part. The terms 'student engagement' 
and 'student motivation' are often used in an interchangable way (e.g. Lin and Gregor, 2006; Oliver and McLaughlin, 1999). Engaged, i.e. motivated students are likely to undergo "deep learning". According to Entwistle (2000; 3), "In the deep learning approach: the intention to extract meaning produces active learning processes that involve relating ideas and looking for patterns and principles on the one hand and using evidence and examining the logic of the argument on the other. The approach also involves monitoring the development of one's own understanding. In the surface approach, in contrast, the intention is just to cope with the task, which sees the course as unrelated bits of information which leads to much more restricted learning processes, in particular to routine memorisation.". This approach hints that highly engaged learning modes and pedagogical choices with the aim of deep learning are best fitted to students with some background and experience of the subject, or at least that students can identify with the subject. Kay and Knaack (2008) suggest that the achievement of high level engagement and thus deeper learning is related to the amount and quality of interaction in a learning object. While Kay and Knaack used web-based tools as learning objects to be examined in their study, the same approach and principle can be applied to other type of learning objects from course workbooks to coaching session agendas.

Another line of research studies the impact of team-based environment to engagement and learning. Teamwork should be conceptually distinguished from any work or learning activity which happens in groups. Ellis and Bell (2005:3) tell that "Organizations are increasingly relying on action or performing teams, which conduct complex, timelimited engagements with audiences, adversaries, or challenging environments in 'performance events' for which teams maintain specialized, collective skill'. A natural question that follows is whether teamwork by students e.g. at undergraduate level can achieve the same learning dynamics as teamwork experienced in the workplace. In their research, Volkov and Volkov (2015) answer that question in the affirmative based on their empirical research and remind also that the effect of teamwork goes beyond the academic learning process to employability and career success. Goddard and Wood (2014) present results that indicate that the deployment by teachers of Modified Team-Based Learning (MTBL) (at both undergraduate and graduate level) has a positive effect on engagement at many levels: student engagement with the subject material, engagement of team members and the teaching of the facilitating team. One recent example from the same educational/institutional context of this study was an international student group competition in Business statistics arranged jointly in 3 universities (JAMK University of Applied Sciences and 2 partner universities from Turkey and Spain). In their analysis Akpinar, Del Campo and Eryarsoy (2014) conclude that collaboration among students that was forced by the setup of the learning method had a positive learning effect.

Interaction, however, should not be seen only as an activity among students or between student(s) and learning objects. As Glückler (2013) points out, comtemporary literature in learning makes a distinction between interactive and non-interactive forms of learning. The interactive form is characterized by businesses building strategic partnerships 
with (other firms and) external knowledge creators in contrast with a lack of reciprocity and two-way transfer of resources in non-interactive learning (Ibid).

Learning processes applying interactive learning methods are often referred to as Problem- or Project-based learning (PBL). Following the ideas of De Graaff and Kolmos (2003), the base of project work lies in the subject-oriented nature of the process, where learning objectives related to subject matter to be learned exist that must get satisfied within the frame of an educational program. Projects must develop skills and knowledge in the learner, and be understood as part of the process of learning that connects with prior learning and post-project learning.

Students who have undergone PBL appear to be well-received by the labour market (Kolmos et al., 2006), while the learning effects of problem/project-based pedagogy have been assessed in various types of contexts. One recent example was presented by Pyykkönen and Kalliomaa (2013) where a PBL-application at the School of Business at JAMK University of Applied Sciences was analyzed. The PBL-method was used in the international lecturing visits to JAMK's partner universities. They found that student feedback was very positive compared to the traditional transmissive pedagogy in place in these universities context in other courses, while the assignors, or "problem-owners" (Finnish companies looking for new markets and ways of market entry) stated they received value from their engagement in the process (ibid.).

Learning processes naturally have immediate learning effects, or produce a short-term gain in knowledge. Research at National Training Laboratories in Bethel, Maine U.S. and earlier work by Dale resulted in Dale's (1994) "learning pyramid of different learning and teaching methods" which posits that higher engagement of the student leads to high level learning of the subject matter. These levels range from solitary reading (the lowest level) to "doing the real thing", indicating that project-based work do has a role in improved learning experience (see figure 1).

Figure 1: Cone of Experience (modified from Dale, 1969)

Another question related to the learning is that of retention - for how long the learners will possess the knowledge gained. Wee Keng Neo (2004) listed the average retention rate of different teaching and learning approaches as follows:

- Lecture

- Reading

- Audiovisual

- Demonstration

- Discussion Group

- Practice by Doing
$5 \%$

$10 \%$

$20 \%$

$30 \%$

$50 \%$

$75 \%$ 
Summarising these studies, the best and most relevant (for professional advancement) learning outcomes for a student can be achieved in a learning setting where elements of team-based work, a real-life problem and intensive interaction between practitioners, students and facilitating teachers can be achieved. In addition, if learners have different experience levels and skill sets at the beginning of the learning process, they can potentially "teach each other" by transferring their knowledge - and thus the highest rate of learning retention can be achieved. 


\section{Case background and implementation}

\section{Foundations and key characteristics of Supercoach ${ }^{\circledR}$ LaunchPad -program}

Background. Supercoach ${ }^{\circledR}$ Entrepreneurial Training (SET) Launch Pad program - later in this paper referred abbreviated as SET - curriculum was formally developed at the request of professors who wanted to educate and coach early stage technology entrepreneurs. Since 2001, SET has been continuously delivered globally as undergraduate, graduate and professional development education for entrepreneurs and instructors/coaches. Coauthor Ballard was inspired to create SET after serving a 10-month Management Fellowship in 1996-97 for the Springboard Program of CONNECT, an entrepreneurial assistance program from the University of California San Diego (UCSD). During her Fellowship, she provided one-to-one coaching to over 60 early stage high technology and life sciences entrepreneurs. The centrepiece of this program was a "springboard" where - after 8 to 10 weeks of weekly coaching sessions - each entrepreneur presented a 15-minute briefing of their business plan to a 'dream' panel of experts tailored for their unique needs. The entrepreneur received an hour of feedback and advice from their dream panel. Springboard became the most supported program at CONNECT (and inspired similar programs often called Launch Pad). Under a Fellowship at University of Strathclyde's Hunter Centre for Entrepreneurship in Glasgow, UK, Ballard formalized and delivered the first SET course with the emphasis on training instructors on this approach used by Ballard at CONNECT.

The SET curriculum was originally developed with a 'train the trainer' focus with the goal of passing on a set of exercises that could be delivered with similar results experienced at UCSD CONNECT without deep educational or entrepreneurship business experience or expertise (business faculty wanted to learn how to educate and coach science and technology based entrepreneurs in a professional development level offering not an academic offering; and economic development organizations wanted to standardize on results with volunteer expert coaches while leveraging the UCSD CONNECT reputation for science-technology venture successes (CONNECT, 2015)

Since the inception of the program in 1993, more than 3000 scientific and technological breakthroughs have been guided through the process of innovation to commercialization. Together, these companies have raised over $\$ 1.4$ billion in capital (ibid.)

Globally, instructors and coaches have been trained by SET: from engineering professors at Arizona State University (ASU) and University of Strathclyde's Hunter Centre for Entrepreneurship to high technology investors and educators in Finland (University of Jyväskylä and Jyväskylä University of Applied Sciences), and from technology transfer 
officers in London to over 115 rural volunteer community coaches as part of the University of Kentucky Entrepreneurial Coaches Institute (KECI). Other SET programs included Venture Well's Advanced Invention to Venture, Baylor University and New Jersey Institute of Technology. Participants from over 300 universities in 30 countries have been trained and coached using SET programs. SET is technology agnostic - it has been successfully applied to all types of entrepreneurial ventures from advanced nanomaterials and medical solutions to ranches and farms.

Relevant for this paper is the important feature of SET: entrepreneurs and coaches are present, and working and learning together (in this case student coaches who are international business students at JAMK). From its inception, SET has always included coaches and entrepreneurs. JAMK's SET Launch Pad Program is led by a Supercoach® instructor for a short classroom training (weekly or twice a week) followed by one-to-one coaching sessions led by a certified SET coach an also joined by JAMK business students who coordinate custom-tailored assistance and networking through the instructor into the community to meet each venture's unique needs. As the Supercoach ${ }^{\circledR}$ Launch Pad Program unfolds, entrepreneurs are first coached by the Supercoach ${ }^{\circledR}$ instructors as the student coaches watch and then gradually the student coaches take more role in coaching, holding entrepreneurs accountable to what entrepreneurs say they want to accomplish, checking for consistencies in the weekly Supercoach ${ }^{\circledR}$ exercises, and helping with business research.

Implementation. SET is an exercise-based approach to helping entrepreneurs think through and articulate all aspects of their business model and plan needed to take their innovation, product or service to market. It is organized into 8 sessions, each with a specific focus. Each session consists of a set of one-page exercises that are deceptive simple: they are actually challenging to complete and often result in considerable backup research. The SET approach uses top-down business planning - an initial business plan is designed and delivered as a 15-minute presentation at the end of a course or weekly coaching sessions over 8 to 12 weeks. The program starts by asking the entrepreneur to express her venture's story as a 30-second elevator speech. This forces them from the beginning to express the essence of their vision: a big opportunity that elicits a desired response, and an answer to the question 'why you?' The story might include the value proposition, what you want from the listener (e.g. investment, a partnership, a customer, etc.), or some other key attribute. Next, the entrepreneur generates a one-page strategic business action plan that is presented to instructors and coaches. From the start of the program entrepreneurs develop and deliver an oral and pictorial presentation of their business plan. A one-page storyboard of the entire business plan presentation is generated in the first series of exercises and presented formally to the instructors and coaches as part of the first session's exercises. 
Over the next 8 to 12 weeks, a series of further exercises force the entrepreneur to do the research necessary to answer typical business plan questions and develop integrated Pro Forma financials. The prototype presentation is enhanced and presented weekly - as more is learned about the market opportunity(s) and as the plan is developed in more detail from the weekly exercises by subject area (technology and IP, marketing and sales, competition and alliances, operations and manufacturing, financials, etc). Because entrepreneurs develop presentations about their business plan, they are able to rapidly produce other documents such as an executive summary or a written business plan that might be required, say, for a competition or venture capital presentation. The SET process is iterative - the process and exercises are designed so that the entrepreneurial team and the student coaches assigned to them can to rapidly rethink the business model, story and plan after each session. With completion of the 8 SET sessions, the entrepreneur has defined all critical aspects of his new venture: strategy, offerings, markets, customers, partners, suppliers, competition, operations, management, financial future and investment requirements, along with critical milestones and risk mitigation strategies. The illustration of the SET program structure can be seen below in Figure 2.

Figure 2: Schematic model of SET program

(from course material handouts, 2014)

What does "coaching" mean in the context of Supercoach ${ }^{\circledR}$ Launch Pad for entrepreneurs? It imparts a gift of skill in viable business creation that entrepreneurs can repeatedly use themselves and pass on to others. Coaching should not be confused with teaching that imparts knowledge in cases where the teacher is the expert and can answer questions and evaluate work. It should not be confused with forms of advising or consulting where experts retain the core skills themselves; or mentoring, where one uses one's personal experience to suggest a specific solution to the mentee's problem. Coaches act as resource facilitators by connecting entrepreneurs to others who can be of value to them. SET instructors and coaches hold entrepreneurs accountable to what entrepreneurs say they want to accomplish; check for consistencies in their business plan thinking using facilitation efforts and enforce the completion not perfection of Supercoach® exercises.

\section{Implementation of 2014 Supercoach ®LaunchPad (SET)-program in Jyväskylä, Finland}

In 2005, the International Business program of JAMK University of Applied Sciences started a specialization track titled High tech Management for $3^{\text {rd }} / 4^{\text {th }}$ year undergraduate home and exchange business students. The track is one semester long ( 5 months). It was developed from dialogue with business practitioners from the surrounding business community with the aim of addressing the future needs of capabilities crucial to foster job 
growth and economic wealth creation. The course consists of four separate modules (High Tech Industry Dynamics, High Tech Marketing, High Tech Strategies, Managing Change and Innovation in High Tech Business) taught as one-month intensive courses in a lecture/masterclass mode, with more case studies and industrial guest speakers than average for the School of Business and other courses in the International Business program. Parallel to that is a fifth module: Implementing a High Tech project. That module has had a big resemblance to traditional project-based learning: Solving individual assignments assigned by companies that naturally have been operative in high tech business.

To further improve the connection to working-life reality and collaborative learning with enterprises, the program's managers decided to integrate a previously separately run intensive 8-week SET entrepreneurial coaching program into the Spring 2014 implementation of the High Tech Management course. The SET program implemented in January to March of 2014 consisted of four intensive full-day seminars where the structure of the whole course and main tools to be utilized in the process were introduced and student were assigned as "assistant coaches" to entrepreneurial teams where their interests and skills matched the needs of the start-up teams. Weekly coaching session facilitated by certified instructors of the coaching program followed the intensive days, where a holistic plan for new tech business development was created via seven separate themes for each session, with exercises which the start-up teams and students collaborated to answer. 


\section{Research method and data collection}

The research approach applied was inductive in nature and utilized case study as a research strategy. Case study - and more precisely single case study - was chosen, since that strategy allows one to go deeply and in a detailed manner in investigating a new and emerging phenomenon (Eisenhardt 1989; Yin 2003), like the unique collaborative learning mode implemented for the first time. It seemed impossible to identify a truly comparable case taking place in the same kind of business context of start-up business. Single case studies are likely to have limitations regarding their generalizability (Siggelkow 2007). However, as the specific nature of the tech-based start-up companies proposes their market opportunity is of global nature and both educator, student as well as entrepreneur cohorts in this case consisted of members on many nationalities and the original scheme of the program is of international making, the results achieved should not be seen solely against the Finnish educational and business context, even though some issues tackled and results derived might be weighted differently if the program was implemented elsewhere.

Primary data was collected via on-line survey tools (Digium in 2014 and Webropol in 2015), which the informants were able to answer anonymously. The weblink to surveys were sent to the informants by e-mail. The researchers were able to see if an individual informant had answered the survey or not (questionnaires in appendices) but was unable to match the answers to a specific informant. This was supposed to enhance the willingness to participate and to answer truthfully to the questions posed.

The survey was done at 3 different time points:

- $\mathrm{t}_{0}=$ Pre-program survey at the start of the first intensive seminar session so before exposure to teaching contents and coaching session in Mid-January 2014

- $\mathrm{t}_{1}=$ Post-program survey right after session 8 (see the program structure in Figure $\mathrm{X})$ i.e. right after the 15-min presentation to the investor panel 8and the feedback by the panel) in early April 2014

- $\mathrm{t}_{2}=$ one-year-post program in March-April 2015

Since the informant pool was limited in numbers, and the sample is close to a census of all participants, a quantitative approach with regression analyses etc. is not appropriate. Thus the results are presented in a descriptive manner, highlighting the differences between $t_{0}, t_{1}$ and $t_{2}$ and between different informant groups like the entrepreneurial team members vs. students and informants who continued with their business idea (until $t_{2}$ ) vs. 
the ones who have been engaged with some other activity between $t_{1}$ and $t_{2}$. Both at $t_{0}$ and $\mathrm{t}_{1}$ the response rate to the survey was above $90 \%$ meaning the sample consisted of appr. 40 informants. The number of informants at $t_{2}$ was 18 . The informants were approached in March-April 2015 to the e-mail address they had given at $t_{0}$ and also by LinkedIn whenever possible - one mail and one reminder containing the short motivation text and the weblink. The loss of some informants can be explained by some students having graduated between $t_{1}$ and $t_{2}$, and as a result the (student) e-mail they had given was not used anymore. Also some start-up teams had not continued their joint work, so the interest towards the subject was most likely diminished. However, the sample of $t_{2}$ had representatives of all 7 start-up cases (both start-up team members and students) that completed the SET in 2014, so also the sample of $t_{2}$ can be regarded as being representative to the case under study.

Since there has been changes of roles related to the situation at $t_{0}$ and $t_{1}$, an additional question was posed related to the main activity between $t_{1}$ and $t_{2}$. The options were numerous but in this analysis they are grouped as follows:

(1) Continued work on the original SET case company (in the tables referred as StartUp Work). This group contains some of the original start-up team members but not all - and some students have continued in the start-up case teams and are not anymore students

(2) Other. This group contains both original start-up members who have worked elsewhere than in the original SET case company and also students (at) who have either continued their studies of got employed oustide the original SET case company.

This division to groups is naturally available only at $\mathrm{t}_{2}$, and due to the anonymous nature of the survey the informants could not anymore be grouped according to the $t_{2}$ in how they had answered the questions at $t_{0}$ and $t_{1}$.

The separate capability areas that were used in the questionnaire were based on the framework of SET program's globally used structure (session titles, also the course material based on this division), and can thus be seen specific to the case under study. The framework has been developed over time and based on the feedback of participants of earlier implementations of SET that has allowed the developers of SET program to conclude that the capability areas addressed are of important nature to start-up development. It can also be stated that the same issue areas are included to curricula of various different academic and non-academic courses about and for entrepreneurship, so the same division could be used for a comparative study when assessing the skill accumulation via other educational set-ups. 


\section{Results}

\section{What are the critical capabilities for start-up development?}

The first question posed to the informants at all 3 measurement points $t_{0}, t_{1}$ and $t_{2}$ (preprogram, post-program, 1-year-post program) was related to the assessment of critical capabilities for start-up development (tables 1 and 2).

First question addressed: How did the participants (students vs. start-up team members) assessed the capability areas crucial for start-up success. Measured Pre-SET-program ( $\left.\mathrm{t}_{0}\right)$, right post-SET $\left(\mathrm{t}_{1}\right)$ and 1 year post-SET $\left(\mathrm{t}_{2}\right)$ :

Table 1: Critical capability areas for start-up development - survey results at $t_{0 .} t_{1}$ and $t_{2}$ (pre-program, post-program, 1-year-post program) - start-up team members vs. students

The key findings from table 1 are that the start-up team members facing a real-life challenge of defining a business plan and model, founding a company etc. see at the start of the program $\left(\mathrm{t}_{0)}\right.$ all capability areas covered in SET program being of very importance to start-up development, and difference in the "weights" they put for each area are small. Overall, the students tend to rate the importance of different areas lower and there is more variation between different capability areas at $t_{0}$. Over time i.e. between $t_{0}, t_{1}$ and $t_{2}$ the start-up team members tend to rank the importance lower whereas students retain the same ratings. Overall assessment (on average across capability areas) varies less among students than start-up team members, who start seeing more differences in importance across capability areas over the stages of learning - as standard deviations show. The importance of "Marketing and Sales" and "Presentation skills" remain high at all-time points in both groups.

Second question addressed: How did the participants (the ones who have continued the work at the start-up company vs. others) assessed the capability areas crucial for start-up success. Measured 1 year post-SET $\left(\mathrm{t}_{2}\right)$ :

Table 2: Critical capability areas for start-up development - survey results at $t_{2}$ - the ones whose main activity between $t_{1}$ and $t_{2}$ has been working with the original SET startup case ("start-up work) vs. other activity

Continued work on the SET start-up case vs. being involved in some other activity has an important effect on the assessed importance to some capability areas. The informants who continued with their case after SET program put at $\mathrm{t}_{2}$ considerable emphasis on "competition and alliance knowledge" as well as to "Operations, management and staffing" and 
"Financial Planning", whereas the informants who have not continued the start-up development process seems to overestimate (compared to the previous group) the role of Presentation skills.

How did the self-assessed skills of participant develop as an effect of the collaborative learning program?

The second area of questions was posed to shed light on the development of the personal skills of the informants who took the SET training. Like in previous tables, the survey results are presented here based on self-assessments given at the 3 measurement points $t_{0}$, $t_{1}$ and $t_{2}$ (pre-program, post-program, 1-year-post program). In table 3 the division of the informants is based on their roles at $t_{0}, t_{1}-$ start-up team members vs. students. In table 4 the division is based on their activity between $t_{1}$ and $t_{2}$. 
First question addressed: How did the participants (students vs. start-up team members) assessed their own skill levels across capability areas. Measured Pre-SET-program ( $\left.\mathrm{t}_{0}\right)$, right post-SET $\left(\mathrm{t}_{1}\right)$ and 1 year post-SET $\left(\mathrm{t}_{2}\right)$ :

Table 3: Self-assessed capability levels across issues areas of SET program-survey results at $t_{0}, t_{1}$ and $t_{2}$ (pre-program, post-program, 1-year-post program) - start-up team members vs. students

It can be undoubtedly stated that with a relatively short but structured 8-week intervention ( $t_{0}$ to $t_{1}$ ) to a start-up process, an impact in capabilities of both members of start-up teams and students can be achieved across all issue areas. Despite the different background of the two groups - start-up teams being "technology-heavy" and students having 2-3 years of business studies behind them before SET - the students rated their skills lower than start-up team members both at the start and right after SET program. Potentially some of their earlier learning in university has shown not to be directly applicable to start-up context. Interestingly, as time goes by, student report to able to maintain and even improve their skill level, whereas start-up team members are giving themselves lower-level assessment one year after SET program. The reasons can be the increased self-criticism and ability of self-assessment vs. real-life needs of the start-up team members. On the other hand there are in many cases additional studies that the student group has taken since SET.

Second question addressed: How did the participants (the one who continued work at the start-up company vs. others) assessed their own skill levels across capability areas. Measured 1 year post-SET $\left(\mathrm{t}_{2}\right)$ :

Table 4: Self-assessed capability levels across issues areas of SET program-survey results at $t_{2}$ - the ones whose main activity between $t_{1}$ and $t_{2}$ has been working with the original SET startup case ("start-up work) vs. other activity

In table 4 above (and when compared to table 3 ) the key finding is that the learners who have needed to bring the learnings from the program to the real-life business context after the program, tend to rank their skill levels lower than those who have not been exposed to start-up business development after SET. However, the skill level ratings the start-up team members who continued with their original case give themselves in e.g. "Operations, Management and Staffing" are higher than the group of the informants who had the role of start-up member at the start of the program. It can be stated that no educational program can fully replace real-life experiential learning in the subject of business development, as the ones who continued their start-up case development have faced and solved these issues in reality.

\section{What capability areas were significantly impacted and was the effect of a lasting} nature? 
Although even minor differences between $t_{0}, t_{1}$ and $t_{2}$ are of interest to organizers and developers of such entrepreneurial programs (e.g. the tendency of start-up team members to rate their skills level lower at $t_{2} 1$ year after the program), not all changes are of statistical significance. The data collected was subjected to Mann-Whitney U-test to those effect in learning that bear significance. The choice of method was done partly by excluding other options: Wilcoxon signed-rank test would have needed the same number of data points from the 2 measurements compared, and the small sample size did not allow standard t-test to be performed. Since both the number (how many informants answered the survey in each round) and identities (which ones of the informant pool answered, since the survey was anonymous and only the status of the informant like student/start-up team member was asked as demographic factor) one-tailed Mann-Whitney U-test was chosen. The results of the test reveal whether two populations - e.g. the students before and after SET-training program - differ significantly in the skill levels they assess themselves to possess. Mann-Whitney U-test also allows small sample sizes to be used. The calculations were done feeding the individual data values to the online Mann-Whitney U-test calculator (Social Science Statistics, 2015).

The Mann-Whitney U-test was run separately to the student and team-member cohorts of the informant pool and 3 comparisons were made for both groups:

- from $t_{0}$ to $t_{1}$ : The immediate short-term effect of the SET-training in the self-assessed skill levels as measured right after the program

- from $t_{1}$ to $t_{2}$ : The deterioration or additional development in self-assessed skill levels between the end of the SET-program and 1 year after the end of SET

- from $t_{0}$ to $t_{2}$ : The long term effect of the SET-training - from the start of the SET program to 1 year after the end of SET

First, the short-term effect of the SET-training was analyzed by comparing the values of between $t_{0}$ and $t_{1}$ measurements i.e. right at the start of the program and immediately after it. Due to the intensity of learning mode is SET-training - all areas covered inside an 8week timeframe - it can be assumed that the major impact to the skill levels assessed was coming from the SET-program, even though the start-up team members were at the same time acting in their business planning in the real-life environment and students had some other learning activities going on outside SET-program.

The results (table 5) show that for the student cohort significant improvement was achieved in 4 out of 7 areas that were separately addressed in the SET curriculum, whereas the improvement was not significant for the remaining 3 areas. The students involved have all taken standard university courses in these 3 subjects as well (like courses in HRM, Management, Financial Management, Management accounting, and kept classroom presentations constantly over the 2-3 years of their study career before SET). One 
interpretation that consideration of the cohort's background allows is that the SET training approach and material has less new viewpoints and tools than the 4 other areas that were positively impacted. On the other hand, students also have learning history of strategic management, marketing and sales courses, so in these areas SET seems to add more to their pre-SET skillset.

Table 5: The short term effect on self-assessed skill levels of students between to and t $t_{1}$

Next, the same short-term effect was tested on the entrepreneurial cohort of the informant pool - the members of the start-up teams (Table 6). From the areas where significant impacts were made 3 (IPR and Tech Management, Marketing and Sales, Competition and Alliance knowledge) matched with the impacts to student cohort. Interestingly also the IPR and Tech Management was impacted despite the fact that most team-members are of science and technology background. It is also quite natural in both cases of student and start-up team cohorts that the capability areas where they assess their starting level at $t_{0}$ to be high, making a significant improvement in limited time is less likely that in those areas where the participants assess their skill level to be low at the start of the training.

Table 6: The short term effect on self-assessed skill levels of start-up team members between $t_{0}$ and $t_{1}$

The analysis of the changes between the measurement of self-assessed skills right after the SET training $\left(\mathrm{t}_{1}\right)$ and 1 year after the end of SET training $\left(\mathrm{t}_{2}\right)$ did not reveal any statistically significant changes, despite the tendencies mentioned earlier: Student tend the report prevailing or improving skill levels vs. the start-up team members who tend to report lower levels of skill as time goes by (see Table 4). The reasons for this and potential solutions are discussed in the next chapters ("Conclusions" and "Discussion"). Due to the non-existence of statistically significant changes the figures from that analysis is not introduced in this paper.

However, the minor changes between $t_{1}$ and $t_{2}$ impacted on the long-term effect of the training. The aim of educators is undoubtedly to create a lasting learning effect so that still after some time (in this case $=1$ year post-SET $=\mathrm{t}_{2}$ ) the learners would report significantly higher levels of skill compared to the start of the training $\left(t_{0)}\right.$. The self-assessed skill levels at $t_{0}$ and $t_{2}$ were also altered to Mann-Whitney U-test. Results in tables 7 (students) and 8 (start-up team members) show that long-term there fewer capability areas where the positive impact had remained. More exactly, for the start-up team members only one capability area (Marketing and Sales) is reported to be on a significantly (statistically) higher level than before the training. For students the same applies to three different capability areas. Potential reasons for this and ideas for solutions for entrepreneurship educators and learners are more closely discussed in the next chapter. 
Table 7: The long term effect on self-assessed skill levels of students between $t_{1}$ and $t_{2}$

Table 8: The short term effect on self-assessed skill levels of start-up team members between $t_{0}$ and $t_{1}$

As it was introduced earlier in the paper the SET entrepreneurial training program has been developed over time and it has been improved based on the participant feedback collected at the end of each implementation (free text comments on the best parts, areas of improvements etc., not analyzed in this paper). This has led to a relatively tight format where the structure, exercise materials, recommended readings as well as practical arrangements like intensive 4-day kick-off followed by weekly coaching sessions are repeated for each case $=$ start-up team + students assigned to them as assistant coaches. Despite that fact the participants in the training making the case for this paper reported relatively uneven skill levels achieved (see standard deviations in table 9 below), especially so in the case of start-up team members. This finding would need additional analysis: Is the deviation due to varying engagement and effort put in by the learners, differences between the coaches or should the coaching approach take more individual approach, addressing the gaps in capabilities specific to each case and learner. The possibilities for that and potential effect to learning arrangements in SET program model are discussed in last chapters of this paper.

Table 9: Standard deviations in the self-assessed skill levels across capability areas at $t_{1}$ (right after the program) 


\section{Conclusions}

The case study done on SET program implementation in Jyväskylä. Finland in 2014 showed that entrepreneurial skills critical to start-up success can be disseminated in a collaborative mode, where normally distinct categories of learners: Technology- and Science-based entrepreneurial teams and business students from undergraduate level get together in a collaborative, team-based and facilitated learning environment. The entrepreneurial teams bring to the learning process live start-up cases around which the experiential learning process can be built as well as their own background and existing skills that in the case of SET most often are from science- and technology domains. The students bring to the process the fresh learnings from their business studies, but often before SET lack the experience of putting their learnings into action, especially in the start-up context.

Both groups, start-up teams as well as students self-assessed a significant improvement in their skills after the intensive 8-week program. However, the self-assessment by the start-up team members one year after the program showed much lower level of skill ratings than those of the students. Further research would be needed to see if there should be additional support and process for learning retention, or is the lowering of the assessed skill level due to the exposure to real-life business challenges leading to a change in what the learners rate as expert-level knowledge etc. Prior-art literature (e.g. Laaksonen. 1995:3) suggests that "self-assessment of the outcomes of affective and cognitive learning takes at the individual level but reflects, at the same time, the individuals' social environments with their events and people. Learning often occurs in social contexts." And since the environment in which the start-up entrepreneurs vs. non-entrepreneurs are supposed to use their learnings from the program is significantly different after the joint learning experience, the bifurcation of the skill levels assessed is quite natural.

Since the context of the case studied in this paper was in Finland. Europe, and thus happening in a specific educational setting and business environment, the findings in this paper cannot be directly generalized to wider range of entrepreneurial programs. Also the special type of companies, first time science -and technology-based entrepreneurs, as well as type of students (business undergraduates) need to be taken in consideration when comparing the achievements of this program to others. Both the start-up team group and group of students (and coaches) consisted of people with multicultural backgrounds, which may support the generalization of the results. Also the SET process itself has been implemented in various continents and countries, so the learning process in this case in not totally unique.

Already in an earlier research paper (Saukkonen. 2014) the course feedback at JAMK University of Applied Sciences for the course High-Tech Management with live projects was shown to get more positive assessment during various years compared to randomly selected courses in the same institution with less interaction with companies. The impact of interaction was notable in the self- assessment of a) achievement of students' learning goals b) the activity the students put into the learning process i.e. student engagement (Ibid.) Furthermore. the 2014 implementation of the High-Tech management course 
where SET program was for the first time inbuilt into the course curriculum, got clearly better overall student feedback than previous years implementations. To students the described mode of learning showed to bear an enhancement to deeper and wider learning (Ibid.). That research did not study the specific impact of SET program to learning inside the course and did not focus on the start-up team members as learners in SET program The study did not either include the retention of learning achieved via SET.

This case study showed that entrepreneurial skills critical to start-up success can be disseminated in a collaborative mode, where normally distinct categories of learners - technology- and science-based entrepreneurial teams and business students from the undergraduate level - work together in a team-based and coach-facilitated learning environment. The entrepreneurial teams bring to the learning process live start-up cases around which the experiential learning process can be built. The students' contribution to the process is their up-to-date theoretical knowledge derived from their "standard" university studies that have not anyhow before SET-program been put into action, especially not in the start-up context.

The study also showed that both groups - start-up teams as well as students - self-assessed improvements in their own skills across given capability areas (derived from the structure of SET program) after the intensive 8-week program. The impact the program was able to make (in a significant magnitude) was not covering all different capability areas in the curriculum, and impact varied between the areas.

Some other interesting phenomena emerged from the research data that requires interpretation and potentially also further research. Firstly, the self-assessment by the start-up team members one year after the SET program showed lowering of skill ratings compared to those right after the program, despite the fact that most informants from that cohort had continued their work in the start-up team and thus a logical expectation would have been a further increase in skills. The student cohort in the informant pool assessed themselves to have maintained or even improved their skill levels better.

Further research would be needed to determine if there should be additional support and process for learning retention, or if the lowering of the assessed skill level is due to the exposure to real-life business challenges leading to a change in what the informants rate as expert-level knowledge etc. Prior-art literature (e.g. Lasonen. 1995:3) suggests that "self-assessment of the outcomes of affective and cognitive learning takes at the individual level but reflects, at the same time, the individuals' social environments with their events and people. Learning often occurs in social contexts." And since the environment in which the start-up entrepreneurs vs. non-entrepreneurs are supposed to use their learning from the program is significantly different after the joint learning experience, the bifurcation of the skill levels assessed would seem quite natural. 
Secondly, not only the coaches using the SET program in entrepreneurial training but all coaches or facilitators in entrepreneurial learning processes can learn from the assessment of critical capability areas when designing entrepreneurial programs: Marketing and sales was the domain that remained on highest level in assessed criticality for start-up success across three different measurement points in time. This was also the area where the significant long term learning effect was achieved for both start-up team member and student cohorts. Additional studies could be done by using the provenly successful technology entrepreneurs as informants: What capability areas they see as crucial for the success achieved?

Thirdly, as was already stated in the literature review, there is no generally agreed set of entrepreneurial skills nor a generally agreed method of when and how the levels in those skills should be measured. We aimed at contributing to the research and practice of entrepreneurship education with our approach, the structure of which was based on one model of an entrepreneurial education - SET. The authors see no major obstacles in utilizing the same methodology to other programs in entrepreneurship. Bearing in mind the multitude of entrepreneurial educational programs, comparative studies of the learning impacts of differently designed programs would help both scholars and practitioners to further develop this special type of Education-Enterprise interaction.

\section{Discussion}

Looking at the method(s) used, the build-up of entrepreneurial capabilities in this study was measured via self-assessment. Having objective tests of skills applicable to start-up development would naturally be a more reliable indicator of achievements and inform the design process of programs in the future. Bearing in mind the complexity of holistic business planning, developing this kind of objective test to replace self-efficacy would take considerable time to develop. As a method of measurement self-assessment has its pitfalls, because the scale one uses to assess one's skills is firstly a personal issue and it also tends to be different at different time points. We do not know exactly but can assume that in the case of asking for self-assessments and when there has been more than 1 year spent on the business ramp-up and that this time and effort reveals additional difficulties; the result is lower grades given to one's own skills upon reflection of the challenges experienced in that year's timeframe. The results give indication this "meeting of the real-life challenges" is an important factor affecting self-assessment, since the student participants who returned to traditional university study mode or work in different type of businesses post-Set, assess themselves having maintained the skill levels better than start-up entrepreneurs who are constantly using those capabilities. Additional research would be needed to confirm this assumption.

Alternatively, we could also assume that there has been a low retention of learning, since we have not been able to continue to coach the participants post-SET program and the 
participants have either had no time or need to revisit the material. This may also potentially be due to a role differentiation in the company that leads to another question to tackle in future research: Should the capabilities of a start-up team be measured on the level of the team or company rather than on individual level? As the start-up company develops, the need for all different team members to master the whole spectrum of skills is likely to diminish.

One optional solution that could be used to overcome the weaknesses of self-assessment could be establishing a third-party expert assessment similar to that which was done in US for a National Science Foundation Study (Suhr et al. 2013) where there was a control and a test group that received over 500 video reviews and assessments made by business and entrepreneurial education experts as to how the teams performed against pre-designed rubrics (the study assessed instructor taught vs. e-learning modules taught). In that case, the experts determined that the teams that were e-learning modules taught performed as well as or outperformed those that were instructor taught.

Also, one option to consider would be to expand the questions more with more descriptive content as to the amount of knowledge each score level would reflect like separating the skills of marketing and sales from each other or diving the IPR and Technology management in to smaller entities, following the structure of program material and coaching session contents. It would be a large task to expand each question but it might significantly improve self-assessment outcomes.

Given that program consists of teams of business study coaches and science-technology based entrepreneurs following a curriculum that with SET coaches/instructors facilitating the process one might conclude that the instructors might not have much impact on the self-assessment scoring. But regarding the results given in table 9, the deviations in the skill levels could be viewed as significant considering all the teams had same time and material in their training. In considering future assessment methods and training and program derivations there would be a need for a method to evaluate if the coaching personality and style impacts these learning outcomes and retention (including some form of coaching/instructor assessment in the mix). The goal of such investigation would be to have more uniform high-level impact on the desired skills to impart both business students and technology entrepreneurs. As already mentioned in the paper the SET program curriculum was originally developed with a 'train the trainer' focus with the goal of passing on a set of exercises that could be delivered with similar results originally experienced at UCSD CONNECT.

This paper describes our initial results in our first attempt to quantify the efficacy of the SET Program; our study generated more questions than answers for the team. For this initial study cohort of student coaches and technology entrepreneurs there are other measures of effectiveness that we could pursue. For example, for the next study cohort we might consider additional questions and follow-up questions that could drive deeper 
insights into learning and the stickiness of the learning, and what additions or changes might be considered to the program delivery and/or curriculum. Another method of measuring efficacy in learning could be the use of independent knowledge and learning assessment against a rubric with the evaluations and efficacy of learning judged by expert judges.

Other measures of effectiveness (MOEs) could be applied to our initial and future cohorts; such MOEs are used by professional investors and used by co-author Ballard and her client academies and accelerators - Return on Investment: how much has the input to the program (monetized) produced output i.e. revenue. Furthermore, universities use initial and long-term salaries and salary growth of their students hired by business to 'grade' their educational value. This could be applied to the initial cohort to tease out additional efficacy measures of the SET training and compare them to students from the same class year. Other measures could include future start-up activities and/or career selections with start-ups and small businesses by the student coaches as well as the technology entrepreneurs. Do they generate more 'start-up' activities in their careers than another cohort that has not been through the training? This type of long term follow-up of start-up entrepreneurs and students that have passed SET (or any other entrepreneurial training) would demand a) traceability of participants over time and b) giving up the anonymity in the initial rounds, since there should be link from one's personal future success to personal assessments done earlier. It should also be taken into account that on the development path of a successful start-up company there are changes in the resources (knowledge, personnel's and board members'/advisors' experience, financing via multiple rounds) and other intervening factors or incidents that linking the business success of a company to any entrepreneurship program participated some years earlier is likely to be a complex and debatable task. 


\section{References}

Aronsson, M. (2004). Education matters - but does entrepreneurship education? An interview with David Birch.Academy of Management Learning and Education. 3(3). 289-292.

Arum, R. \& Roska, J. (2011) Academically Adrift:Limited Learning on College Campuses. Chicago. University of Chicago Press

Astin. A. (1993).What Matters for College? Four Critical Years Revisited. Jossey-bass. San Francisco. CA.

Brown, A., Rich, M. and Holtham, C.. (2014) Student engagement and learning: Case study of a new module for business undergraduates at Cass business school. Journal of Management Development. Vol. 33 Iss: 6. pp.603-619

CONNECT (2015): Sringboard. Available (online): http://connect.org/entrepreneurs/springboard/ (13 August 2015)

Corbett, A. C. (2005). Experiential learning within the process of opportunity identification and exploitation. Entrepreneurship: Theory \& Practice. 29(4). 473-491.

Dale, E. (1969). Audio-visual Methods in Teaching. 3rd edition. New York: The Dryden Press; Holt, Rinehart and Winston

De Graaff, E. \& Kolmos. A. (2003). Characteristics of Problem-Based Learning. International Journal of Engineering Education. 19(5). 657-662.

Eisenhardt, K. M. (1989). Building theories from case study research. Academy of Management Review. 14(4). 532-550.

Ellis, A.P.J. \& Bell, B.S. (2005). An Evaluation of Generic Teamwork Skills Training with ActionTeams: Effects on Cognitive and Skill-Based Outcomes. Personnel Psychology. vol. 58. no. 3.pp. 641-72.

Entwistle, N.J. (2002). Promoting Deep Learning through Teaching and Assessment: Conceptual Frameworks and Educational Contexts. Paper to be presented at TLRP Conference. Leicester. November. 2000 available (online): http://www.tlrp.org/acadpub/Entwistle2000.pdf

Etzkowitz, H. \& Leydesdorff, L. (1995). The Triple Helix -- University-Industry-Government Relations: A Laboratory for Knowledge Based Economic Development EASST Review. Vol. 14. No. 1. pp. 14-19.

European Commision (2012): Do SMEs create more and better jobs? January. 2012. Available (online): http://europa.eu/rapid/press-release_MEMO-12-11_en.htm (10 August 2015)

Fiet, J. O. (2000). The theoretical side of teaching entrepreneurship. Journal of Business Venturing. 16. $1-24$.

Fine, C. H. (2008). Clockspeed: Winning Industry Control in the Age of Temporary Advantage. Perseus Book Group

Garavan, T. N. \& O'Cinneide, B. (1994). Entrepreneurship education and training programs: A review and evaluation part 1. Journal of European Industrial Training. 18(8). 3-12.

Gibbs, G. (2010) Dimensions of Quality. The Higher Education Academy (HEA). York 
Glückler, J. (2013). Knowledge. Networks and Space: Connectivity and the Problem of Non-Interactive Learning. Regional Studies Vol. 47. Issue 6. 2013. 880-894.

Goddard, A. and Wood, C. (2014). From passive to active learning: A case study using a modified teambased learning approach Employment Relations Record. Vol. 14. No. 1. Aug 2014: 26-39.

Gompers, P., Kovner, A., Lerner, A. and Scharfstein, D. (2006) Skill vs. Luck in Entrepreneurship and Venture Capital: Evidence from Serial Entrepreneurs. NBER Working Paper No. 12592 Issued in October 2006. Available (online): http://www.people.hbs.edu/dscharfstein/Working\%20Papers/Skill_vs_Luck.pdf (15 April 2015)

Jones. S. \& Clulow. S. (2012). How to foster a culture of collaboration between universities and industry. available (online) http://www.theguardian.com/higher-education-network/blog/2012/aug/02/the-value-ofresearch-collaborations._(12 August 2014)

Kauffman Foundation (2010): The Importance of Startups in Job Creation and Job Destruction. available (online)http://www.kauffman.org/what-we-do/research/firm-formation-and-growth-series/theimportance-of-startups-in-job-creation-and-job-destruction (10 April 2015)

Kauffman Foundation. (2013) Young hightech firms outpace private sector job creation. available (online) http://www.kauffman.org/newsroom/2013/08/young-hightech-firms-outpace-privatesector-job-creation $\left(28^{\text {th }}\right.$ October 2014$)$

Kay, R.H. \& Knaack, L. (2009): Assessing learning, quality and engagement in learning objects: the Learning Object Evaluation Scale for Students (LOES-S). Education Tech Research Dev 57:147-168

Kleine, R. \& Yoder, J-D. (2013): Spreading the Fire: Broadening Faculty Support for the Entrepreneurial Mindset.Conference paper at OPEN 2013: NCIIA's 17th Annual ConferenceMarch 22-23. Washington. DC. Available (online) http://nciia.org/sites/default/files/features/conference/2013/papers/yoder.pdf (3 April 2015)

Lasonen, J. (1995). A Case Study of Student Self-Assessment in Upper Secondary Education. Contemporary Issues of Occupational Education in Finland. University of Jyväskylä: 199-215

Lin, A. \& Gregor, S. (2006). Designing websites for learning and enjoyment: A study of museum experiences.International Review of Research in Open and Distance Learning. 7(3). 1-21.

Marmer, M.. Herrmann, B.L., Dogrultan, E. and Berman, R. (2011) A New framework for understanding why start-up succeed.Start-Up Genome Report. available(online)

http://gallery.mailchimp.com/8c534f3b5ad611c0ff8aeccd5/files/Startup_Genome_Report_version_2.1 .pdf (15 February 2014)

Mohr, J.J., Sengupta, S. and Slater, S.F. (2010). Marketing of High-technology Products and Innovations. 3rd edition. Pearson Prentice Hall.

Oliver, R. \& McLoughlin, C. (1999). Curriculum and learning-resources issues arising from the use of webbased course support systems. International Journal of Educational Telecommunications. 5(4). 419435.

Pyykkönen, R. \& Kalliomaa, S. (2013). PBL Applications in the BBA programme in Business Administration in the School of Business and Services Management at JAMK University of Applied Sciences. Finland. PBL across Cultures. Aalborg University Press. 
Ries, E. (2011). The Lean Start-Up. Crown Publishing.

Saukkonen, J. (2014). Effects of project-based learning in education-enterprise collaboration to learning experience and student engagement. Available (online): http://verkkolehdet.jamk.fi/finnish-business-review/files/2015/01/manucsript-4-revised-final-.pdf Finnish Business Review (December 16. 2014)

Siggelkow, N. (2007). Persuasion with case studies. Academy of Management Journal. 50(1). 20-24.

Social Science Statistics (2015): available (online): http://www.socscistatistics.com/tests/mannwhitney/Default2.aspx (August 11. 2015)

Suhr. D., Ballard. S., Gomez. R., Ryng. H., \& Shartrand. A. 2013. The Way Entrepreneurs Learn: Migration of a 30-Second Elevator Pitch Exercise from Instructor-Led Delivery to Blended Learning Technology. Paper presented at the meeting of the NCIIA - Open 2013. Washington D.C. available (online): http://apps.nciia.org/sites/default/files/u7/suhr.pdf_(13 August 2015)

Volkov, A. and Volkov, M (2015). Teamwork benefits in tertiary education: student perceptions that lead to best practice assessment design. Education + Training. Vol. 57 Iss 3 pp.

Wee, Keng Neo Lynda (2004). A problem-based learning approach in entrepreneurship education: promoting authentic entrepreneurial learning. IJTM 28(7/8): 685-701

Yin, R. K. (2003). Case study research: Design and methods. Thousand Oaks. California: Sage. 


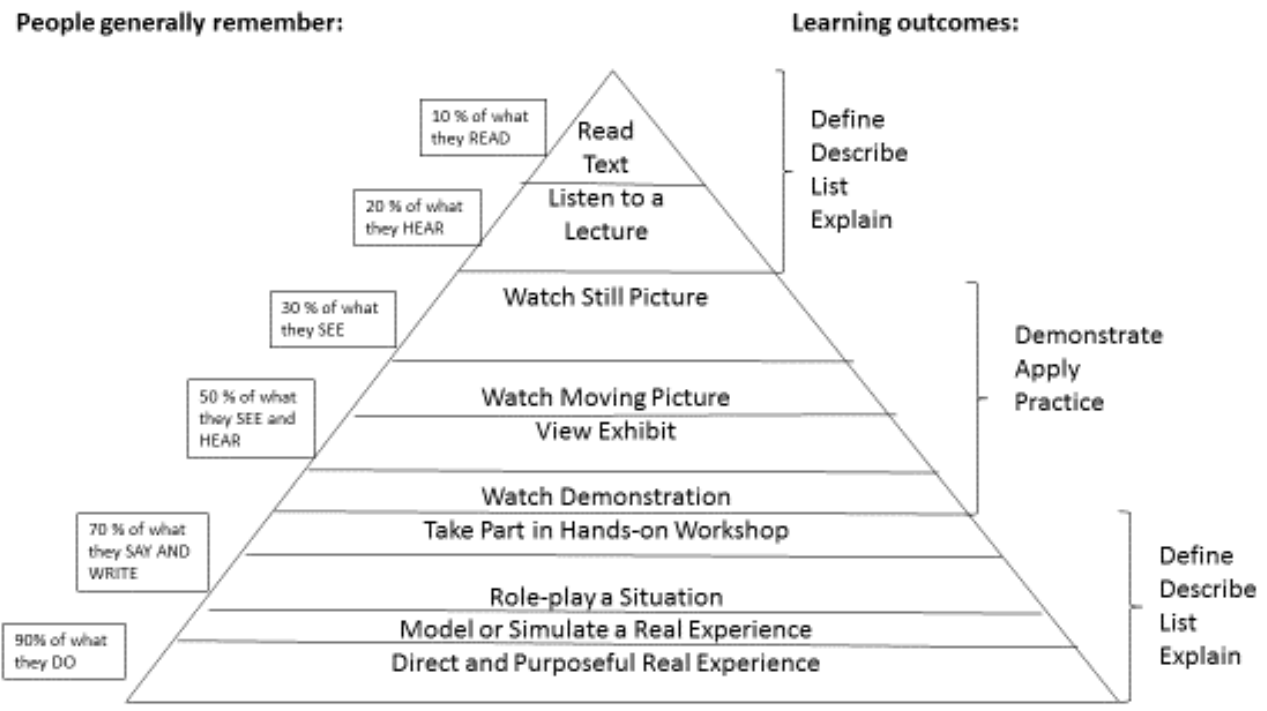

Figure 1 


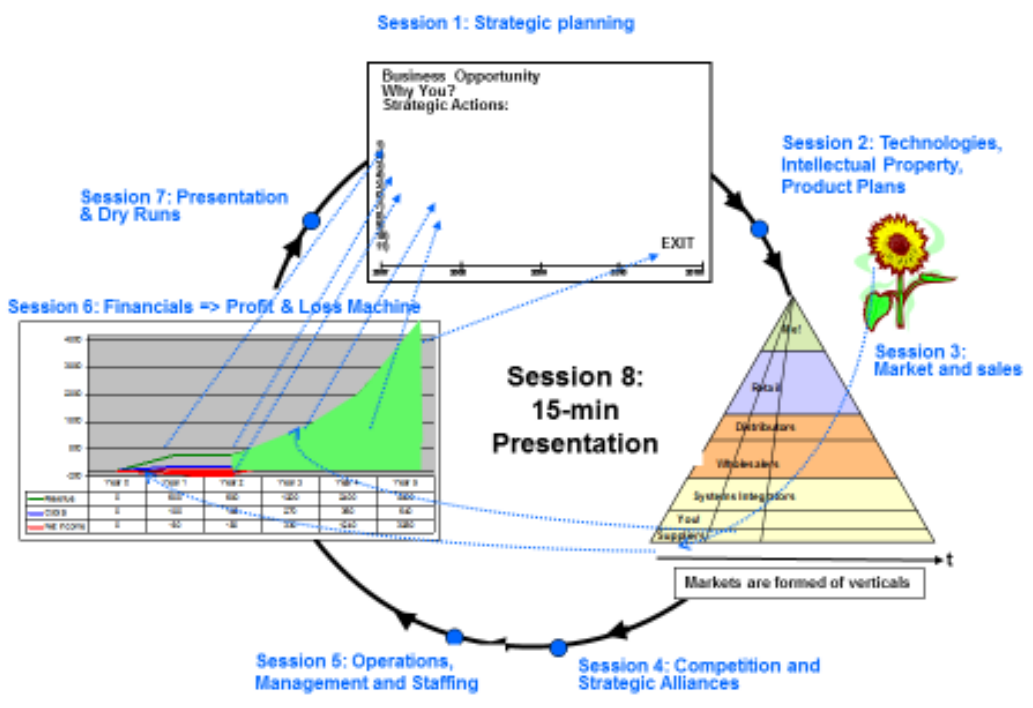

Figure 2 
Question 1: Importance of different capability areas for start-up development (Scale: 1 = not important at all $<=>5=$ extremely important)?

\begin{tabular}{|c|c|c|c|c|c|c|}
\hline \multirow[b]{2}{*}{ CAPABILITY AREA } & \multicolumn{2}{|l|}{ t0 Pre-Program } & \multicolumn{2}{|c|}{ t1 Post-Program } & \multicolumn{2}{|c|}{ t2 1-year- Post-Program } \\
\hline & $\begin{array}{l}\text { Start-up team } \\
\mathrm{n}=7\end{array}$ & $\begin{array}{l}\text { Students } \\
\mathrm{n}=20\end{array}$ & $\begin{array}{l}\text { Start-up team } \\
n=11\end{array}$ & $\begin{array}{l}\text { Students } \\
\mathrm{n}=17\end{array}$ & $\begin{array}{l}\text { Start-up team } \\
n=8\end{array}$ & $\begin{array}{l}\text { Students } \\
\mathrm{n}=10\end{array}$ \\
\hline Strategic Planning & 4.71 & 4.45 & 4.45 & 4.35 & 3.75 & 4.5 \\
\hline IPR and tech management & 4.14 & 4 & 3.45 & 4 & 3.38 & 3.9 \\
\hline Marketing and sales & 4.86 & 4.5 & 4.64 & 4.47 & 4.63 & 4.4 \\
\hline $\begin{array}{l}\text { Competition and alliance } \\
\text { knowledge }\end{array}$ & 4.29 & 4.1 & 3.64 & 4.29 & 3.63 & 4 \\
\hline $\begin{array}{l}\text { Operations. management and } \\
\text { staffing }\end{array}$ & 4.29 & 3.9 & 4 & 3.76 & 3.5 & 3.9 \\
\hline Financial Planning & 4.43 & 4.15 & 4.09 & 4.35 & 4 & 4.4 \\
\hline Presentation skills & 4.71 & 3.9 & 4.18 & 4.06 & 4.38 & 4.4 \\
\hline Average & 4.49 & 4.14 & 4.06 & 4.18 & 3.89 & 4.18 \\
\hline standard deviation & 0.25 & 0.23 & 0.39 & 0.23 & 0.43 & 0.25 \\
\hline
\end{tabular}

Table 1 
Question 1: Importance of different capability areas for start-up development (Scale: 1 = not important at all $\Leftrightarrow=>$ = extremely important)

\begin{tabular}{|l|l|l|l|}
\cline { 2 - 3 } \multicolumn{2}{l|}{} & t2 1-year- Post-Program & \multicolumn{1}{l}{} \\
\hline CAPABILITY AREA & $\begin{array}{l}\text { Start-up work } \\
\mathrm{n}=7\end{array}$ & $\begin{array}{l}\text { Other } \\
\mathrm{n}=11\end{array}$ & \multicolumn{1}{c}{$\Delta$} \\
\hline Strategic Planning & 4.14 & 4.18 & 0.04 \\
\hline IPR and tech management & 3.71 & 3.64 & 0.07 \\
\hline Marketing and sales & 4.57 & 4.45 & 0.12 \\
\hline Competition and alliance knowledge & 3.57 & 4 & 0.43 \\
\hline Operations. management and staffing & 4.14 & 3.45 & 0.69 \\
\hline Financial Planning & 4.43 & 4.1 & 0.33 \\
\hline Presentation skills & 4 & 4.6 & 0.6 \\
\hline Average & 4.08 & 4.06 & 0.02 \\
\hline std deviation & 0.33 & 0.38 & \\
\cline { 1 - 3 } & & & \\
\end{tabular}

Table 2 
Question 2: Rate your skill level in the different capability areas Scale: (1=no knowledge $<=>5=$ expert knowledge)

\begin{tabular}{|c|c|c|c|c|c|c|}
\hline \multirow[b]{2}{*}{ CAPABILITY AREA } & \multicolumn{2}{|l|}{ to Pre-Program } & \multicolumn{2}{|c|}{ t1 Post-Program } & \multicolumn{2}{|l|}{$\begin{array}{l}\text { t2 1-year- Post } \\
\text { Program }\end{array}$} \\
\hline & $\begin{array}{l}\text { Start-up team } \\
n=7\end{array}$ & $\begin{array}{l}\text { Students } \\
n=20\end{array}$ & $\begin{array}{l}\text { Start-up team } \\
\mathrm{n}=11\end{array}$ & \begin{tabular}{|l|} 
Students \\
$\mathrm{n}=17$
\end{tabular} & $\begin{array}{l}\text { Start-up team } \\
\mathrm{n}=8\end{array}$ & $\begin{array}{l}\text { Students } \\
\mathrm{n}=10\end{array}$ \\
\hline Strategic Planning & 3.29 & 2.84 & 3.73 & 3.47 & 3.63 & 3.8 \\
\hline IPR and tech management & 2.71 & 1.8 & 3.64 & 3.24 & 3.25 & 3.3 \\
\hline Marketing and sales & 2.43 & 3.15 & 4 & 3.78 & 3.88 & 3.8 \\
\hline Competition and alliance knowledge & 2.71 & 2.45 & 3.82 & 3.53 & 3.8 & 3.8 \\
\hline Operations. management and staffing & 3.14 & 3.05 & 3.55 & 3.53 & 3 & 3.5 \\
\hline Financial Planning & 3 & 2.7 & 3.64 & 3.18 & 3.25 & 3 \\
\hline Presentation skills & 3.29 & 3.5 & 3.55 & 3.82 & 3.63 & 3.9 \\
\hline Average & 2.94 & 2.78 & 3.7 & 3.5 & 3.41 & 3.59 \\
\hline standard deviation & 0.33 & 0.55 & 0.15 & 0.22 & 0.30 & 0.31 \\
\hline
\end{tabular}

Table 3 
Question 2: Rate your skill level in the different capability areas

(Scale: $1=$ no knowledge $<=>5=$ expert knowledge)

\begin{tabular}{|c|c|c|c|}
\hline \multirow{2}{*}{ CAPABILITY AREA } & \multicolumn{2}{|c|}{ t2 1-year- Post-Program } & \multirow[b]{2}{*}{$\Delta$} \\
\hline & $\begin{array}{l}\text { Start-up work } \\
\mathrm{n}=7\end{array}$ & \begin{tabular}{|l|} 
Other \\
$n=11$
\end{tabular} & \\
\hline Strategic Planning & 3.57 & 3.82 & 0.25 \\
\hline IPR and tech management & 3.29 & 3.27 & 0.02 \\
\hline Marketing and sales & 3.86 & 3.82 & 0.04 \\
\hline Competition and alliance knowledge & 3.29 & 3.73 & 0.44 \\
\hline Operations. management and staffing & 3.29 & 3.27 & 0.02 \\
\hline Financial Planning & 3.14 & 3.09 & 0.05 \\
\hline Presentation skills & 3.29 & 4.09 & 0.8 \\
\hline Average & 3.39 & 3.58 & 0.19 \\
\hline standard deviation & 0.23 & 0.34 & \\
\hline
\end{tabular}

Table 4 
Students: changes from Pre-SET-program to-Post-SET (self-assessed skill levels)

\begin{tabular}{|l|c|c|c|c|}
\hline Capability area & U-value & Z-score & p-value & Significant at $\mathbf{p} \leq \mathbf{0 . 0 5} ?$ \\
\hline Strategic Planning & 93.5 & -2.1389 & 0.01618 & yes \\
\hline IPR and Tech Management & 42.5 & -3.37555 & $9.00 \mathrm{E}-05$ & yes \\
\hline Marketing and Sales & 112 & -1.7524 & 0.04006 & yes \\
\hline $\begin{array}{l}\text { Competition and alliances } \\
\text { knowledge }\end{array}$ & 67 & -3.1238 & 0.0009 & yes \\
\hline $\begin{array}{l}\text { Operations. management and } \\
\text { staffing }\end{array}$ & 116.5 & -1.6152 & 0.05202 & no \\
\hline Financial Planning & 124.5 & -1.3714 & 0.08534 & no \\
\hline Presentation skills & 135 & -1.0514 & 0.14686 & no \\
\hline
\end{tabular}

Table 5 
Start-Up Team Members: changes from

Pre-SET-program to-Post-SET (self-as-

sessed skill levels)

\begin{tabular}{|l|c|c|c|c|}
\hline Capability area & U-value & Z-score & p-value & $\begin{array}{c}\text { Significant at } \\
\text { p } \leq \mathbf{0 . 0 5} ?\end{array}$ \\
\hline Strategic Planning & 38 & 1.1321 & 0.12924 & no \\
\hline IPR and Tech Management & 28.5 & 2.5359 & 0.00554 & yes \\
\hline Marketing and Sales & 39.5 & 2.9887 & 0.00139 & yes \\
\hline $\begin{array}{l}\text { Competition and alliances } \\
\text { knowledge }\end{array}$ & 27.5 & 2.3095 & 0.01044 & yes \\
\hline $\begin{array}{l}\text { Operations. management and } \\
\text { staffing }\end{array}$ & 29 & 1.0868 & 0.13786 & no \\
\hline Financial Planning & 30.5 & 1.4038 & 0.0876 & no \\
\hline Presentation skills & 41.5 & 0.643 & 0.26435 & no \\
\hline
\end{tabular}

Table 6 
Students: changes from Pre-SET program to 1 year Post-SET program (self-assessed skill levels)

\begin{tabular}{|l|c|c|c|c|}
\hline Capability area & $\begin{array}{l}\text { U- } \\
\text { value }\end{array}$ & Z-score & p-value & Significant at $\mathbf{p} \leq \mathbf{0 . 0 5} ?$ \\
\hline Strategic Planning & 36 & -2.6284 & 0.00368 & yes \\
\hline IPR and Tech Management & 24.5 & -3.2996 & 0.0048 & yes \\
\hline Marketing and Sales & 65.5 & -1.4958 & 0.0681 & no \\
\hline $\begin{array}{l}\text { Competition and alliances } \\
\text { knowledge }\end{array}$ & 30 & -3.0576 & 0.00111 & yes \\
\hline $\begin{array}{l}\text { Operations. management and staff- } \\
\text { ing }\end{array}$ & 65 & -1.5178 & 0.06426 & no \\
\hline Financial Planning & 79 & -0.9019 & 0.18406 & no \\
\hline Presentation skills & 74.5 & -1.0999 & 0.13567 & no \\
\hline
\end{tabular}

Table 7 
Start-Up team members - changes from

Pre-SET program to 1 year Post-SET pro-

gram (self-assessed skill levels)

\begin{tabular}{|l|c|c|l|c|}
\hline Capability area & U-value & Z-score & p-value & Significant at $\mathbf{p} \leq \mathbf{0 . 0 5} ?$ \\
\hline Strategic Planning & 22.5 & 0.5786 & 0.28096 & no \\
\hline IPR and Tech Management & 18.5 & 1.0415 & 0.14917 & no \\
\hline Marketing and Sales & 6 & 2.4881 & 0.00639 & yes \\
\hline $\begin{array}{l}\text { Competition and alliances } \\
\text { knowledge }\end{array}$ & 17 & 1.2151 & 0.11123 & no \\
\hline $\begin{array}{l}\text { Operations. management and staff- } \\
\text { ing }\end{array}$ & 25.5 & -0.2315 & 0.40905 & no \\
\hline Financial Planning & 24.5 & 0.3472 & 0.36317 & no \\
\hline Presentation skills & 21 & 0.7522 & 0.22663 & no \\
\hline
\end{tabular}

Table 8 


\begin{tabular}{|c|c|c|c|c|c|c|}
\hline $\begin{array}{l}\text { Deviations of the self-assessed } \\
\text { skill levels across capability } \\
\text { areas. Measured at Post-SET } \\
\left(t_{1}\right)\end{array}$ & \multicolumn{3}{|c|}{ STUDENTS } & \multicolumn{3}{|c|}{ START-UP TEAM MEMBERS } \\
\hline Self-assessed Own skill levels & & Ave & Std Dev & & Ave & Std Dev \\
\hline Strategic Planning & & 3.47 & 0.62 & & 3.19 & 0.90 \\
\hline IPR + Tech Management & & 3.24 & 0.83 & & 2.94 & 0.96 \\
\hline Marketing and Sales & & 3.76 & 0.83 & & 3.35 & 0.91 \\
\hline $\begin{array}{l}\text { Competition and Alliance } \\
\text { knowledge }\end{array}$ & & 3.53 & 0.72 & & 3.20 & 0.89 \\
\hline $\begin{array}{l}\text { Operations. Management and } \\
\text { Staffing }\end{array}$ & & 3.53 & 0.80 & & 3.15 & 0.85 \\
\hline Financial Planning & & 3.18 & 0.88 & & 2.75 & 0.71 \\
\hline Presentation skills & & 3.82 & 0.53 & & 3.52 & 0.91 \\
\hline & average & 3.50 & 0.75 & average & 3.16 & 0.87 \\
\hline
\end{tabular}

Table 9 